\title{
Professor John Fitzpatrick in memoriam
}

\author{
H. G. Tiselius · W. G. Robertson
}

Received: 20 July 2014 / Accepted: 28 July 2014 / Published online: 2 September 2014

(C) Springer-Verlag Berlin Heidelberg 2014

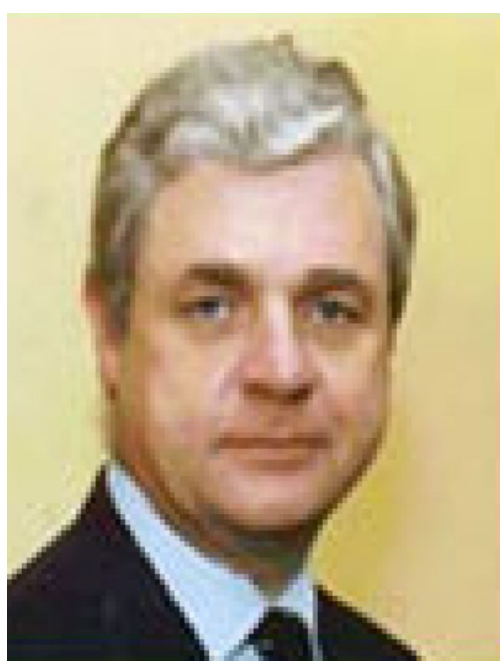

John Fitzpatrick

It was with great sadness that we recently learned of the passing of Professor John Fitzpatrick. His sudden and unexpected death is a great loss, not only to his close family but also to the whole urological community.

During his more than 40 years long clinical and academic career, he was extremely active and made considerable contributions to urology—clinically as well as scientifically. His impressive record of research and substantial publication list of peer-reviewed articles, book chapters and books is only a small reflection of his enormous gift to various areas

H. G. Tiselius

Stockholm, Sweden

W. G. Robertson $(\bowtie)$

Harrogate, UK

e-mail: robertsonwilliam67@gmail.com of urology and to patients with a wide range of urological diseases.

Following studies at University College Dublin and initial clinical education there, he was trained by worldleading experts in urology in a several well-recognized institutions in London and Mainz. He was born in Dublin and returned to Dublin, where in 1986, he was appointed Professor and Chairman of the Department of Surgery in the Mater Misericordiae Hospital and University College Dublin School of Medicine and Medical Science.

John Fitzpatrick was the Editor-in-Chief of BJU International for several years and under his leadership, the journal developed to be one of the best urological journals in the world. He was an excellent speaker and became honorary member of numerous colleges and associations worldwide. Following his retirement in 2012, he became the Head of Research at the Irish Cancer Society and with his enthusiasm and energy he obviously had a lot more to give in this area.

It was a great honour for our Journal (when it was still Urological Research) to share his outstanding clinical and scientific expertise when he was a member of the Editorial Board during a period when all branches of urological research were within the scope of the Journal. His valuable input was of considerable importance in maintaining a high standard of quality of the articles published at that time.

Professor John Fitzpatrick will be missed by colleagues in the urological and associated fields throughout the world and at this difficult time our thoughts and support go out to his family. 